\title{
Short Courses and Workshops
}

\section{JCPDS - International Centre for Diffraction Data Short Course on Search/Match Methods}

The JCPDS-International Centre for Diffraction Data will continue to offer three day short courses on Search/Match methods at the Swarthmore, PA, headquarters of the International Centre.

The courses, which are now in their 5th year, are intended to build proficiency of the user in the interpretation of experimental data, especially in the application of the information provided in the Powder Diffraction File. The courses should be useful to the novice as well as the experienced powder diffractionist, and all discussions start with the basic principles leading on to useful laboratory procedures. Workbooks are provided to all attendees and these contain a number of experimentally obtained X-ray diffraction data sets which are used as class exercises. During the workbook sessions, the classes are subdivided to match the needs and experience of the attendees.

The course will emphasize the nature and organization of the information in the Powder Diffraction File and retrieval and use of this information for interpreting experimentally collected diffraction data. The implications of the accuracy of measurement of d-spacings, and intensities of experimental data with respect to use of the powder file will be discussed, as well as common instrumentation and specimeninduced errors. The use of both manual and computer search/match methods for phase indentification will be practiced through the use of workbooks. Applications of File data for further characterizing phases will be illustrated using several mineralogical problems and a special X-ray diffraction minerals workbook. Other types of materials may be studied including organic and forensic materials, depending upon the needs of the participants.

\section{Course Schedule}

First day Morning

Optimization of data collection

Evaluation of experimental diffraction data

Instrument-induced errors

Sample-induced errors

Afternoon Introduction to the Powder Diffraction File

Alphabetic search procedures

Hanawalt search procedures

Second day

Morning

Fink search procedures

Classical powder diffraction problems

Phase identification

Afternoon Phase identification in polyphase samples

Solid-solution analysis

d-Spacing calibration
Third day

Morning Indexing of powder data

Quantitative analysis

Mineral problems

Afternoon Computer retrieval of identifications

For further information please contact:

Ms. Josephine Felizzi

JCPDS - International Centre for Diffraction Data

1601 Park Lane

Swarthmore, PA 19081, U.S.A.

(215) 328-9403

The cost of a course is $\$ 550.00$ which includes textual materials and lunches. Lodging, transportation and other costs are at the expense of the attendee.

\section{Special Topics in X-Ray Diffraction}

September 17, 1986

Washington, DC

A one-day complimentary seminar will be sponsored by Siemens Energy \& Automation on developments in X-ray diffraction. The emphasis of the seminar will be on texture and ODF analysis. Details can be obtained from Kristine Brown, (609) 424-9210.

\section{JCPDS - International Centre for Diffraction Data}

Course Schedules

\section{6}

September 30 to October 2

International Centre Headquarters

Swarthmore, PA, U.S.A.

December 2-4

Los Angeles, CA, U.S.A.

\section{7}

February 10-12

Mid-West (Venue to be arranged)

Dallas, Texas

April 21-23

International Centre Headquarters

Swarthmore, PA, U.S.A. 